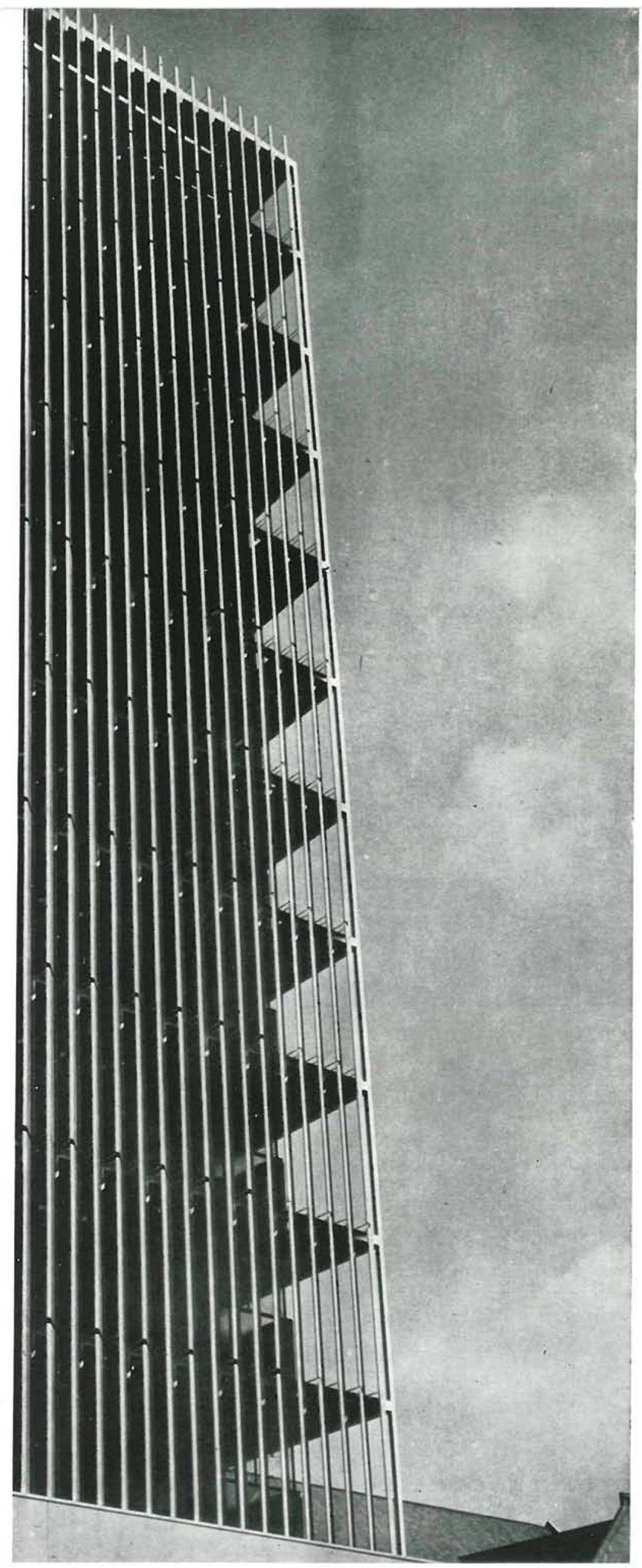

\title{
edificio de oficinas, en los Angeles
} VICTOR GRUEN, arquitecto

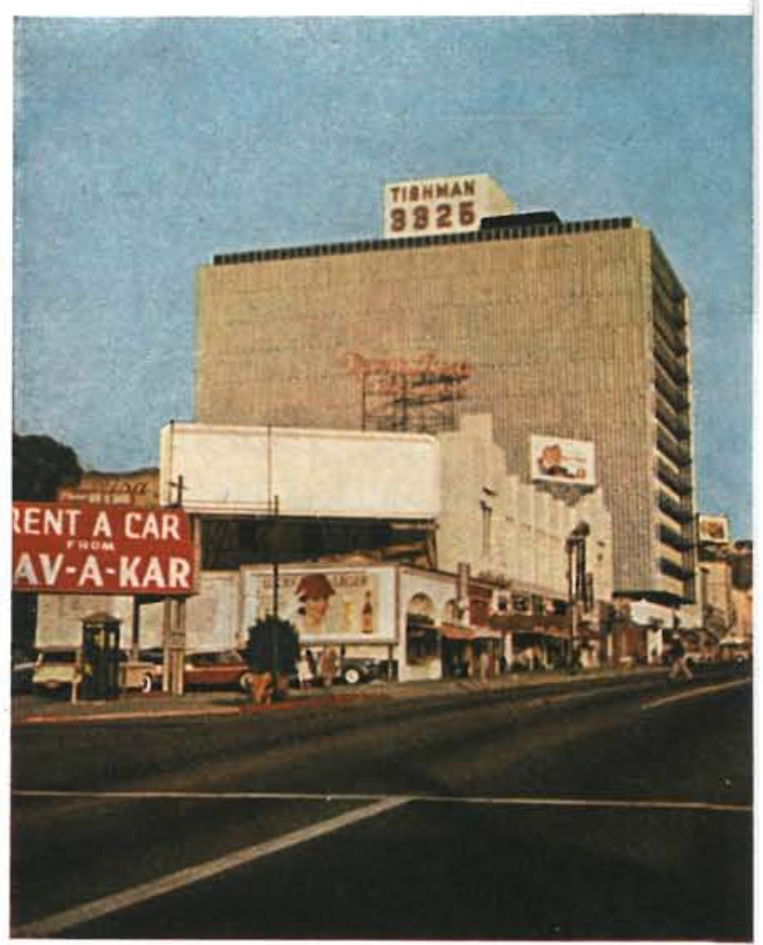




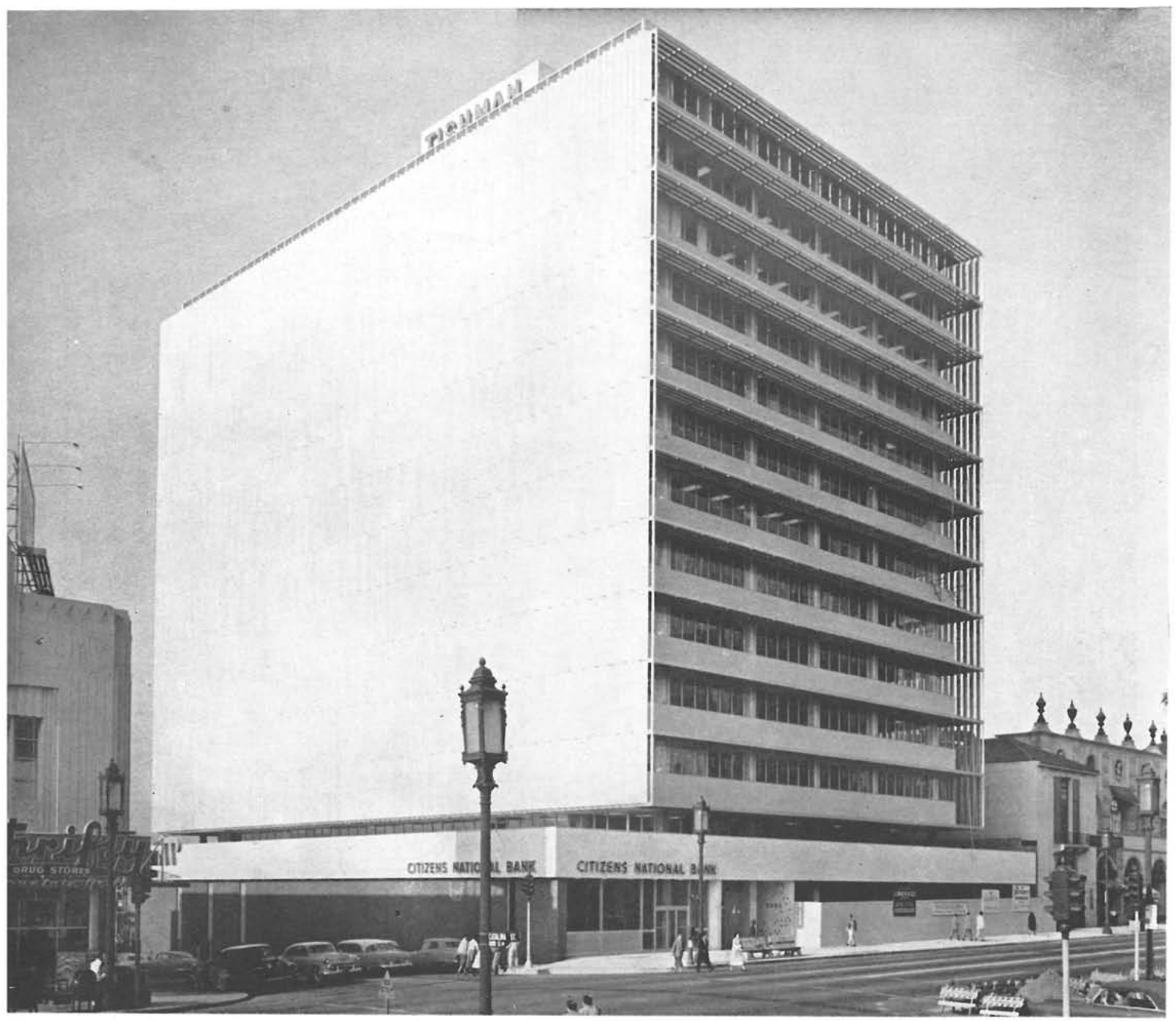

Dentro del concepto arquitectónico más actual, escueto de líneas y tendiendo claramente a la forma elemental prismática, este edificio exhibe su silueta calada en medio de la populosa ciudad californiana, contrastando, de manera ostensible, con sus desordenados vecinos, cuyos volúmenes de edificación y caracteres dan variedad estridente al bulevar Wilshire, en el que ocupa el número 3.325.

La composición de masas-simple y clara-está basada en las nuevas ordenanzas de la ciudad de Los Angeles, que permiten aprovechar trece veces la superficie del terreno, sin limitaciones de altura, y lejos de las absurdas medianerías ciegas. Gracias a ello se ha podido conseguir la construcción de este edificio, cuya composición exterior está plenamente justificada por conseguir interiores más confortables.

El triunfo de las estructuras metálicas y de hormigón armado, así como el desarrollo del aire acondicionado, permitieron liberar a la fachada de su función resistente y de aislamiento térmico, pasando a ser un elemento transparente, que nada opone a la entrada de la luz y del sol.

A esta arquitectura abierta, de limpios paramentos de cristal, consagrada por magníficos ejemplos de la arquitectura de hoy, opone víctor Gruen su solución de doble fachada: una, totalmente vidriada, limpia y luminosa; y otra, de persiana fija exterior, de elementos laminares de aluminio.

INSTITUTO TECNICO DE LA CONSTRUCCION Y DEL CEMENTO 
pla $n$ t a

baja

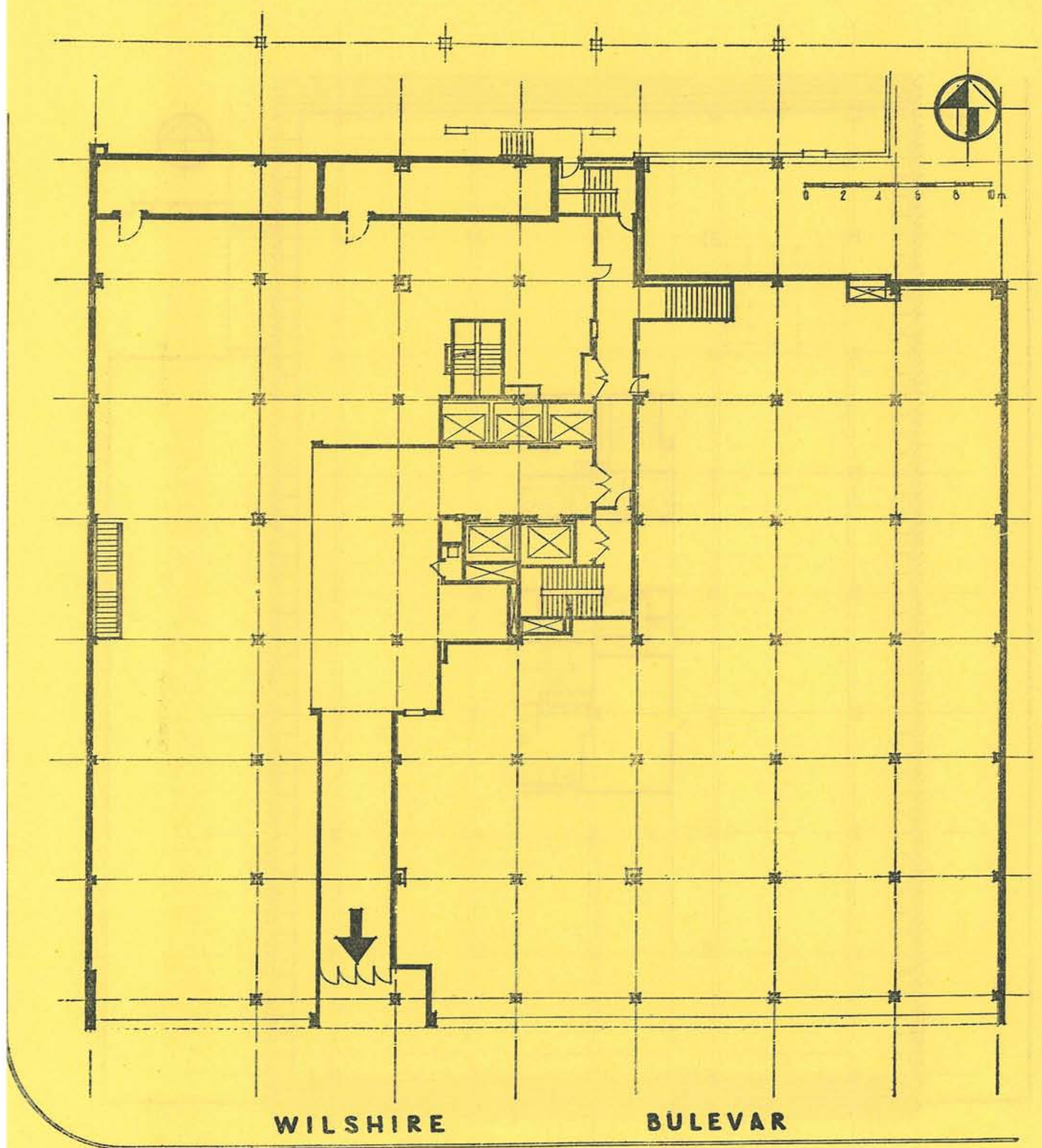




\section{pla $\operatorname{ara}$}

\section{tipo}

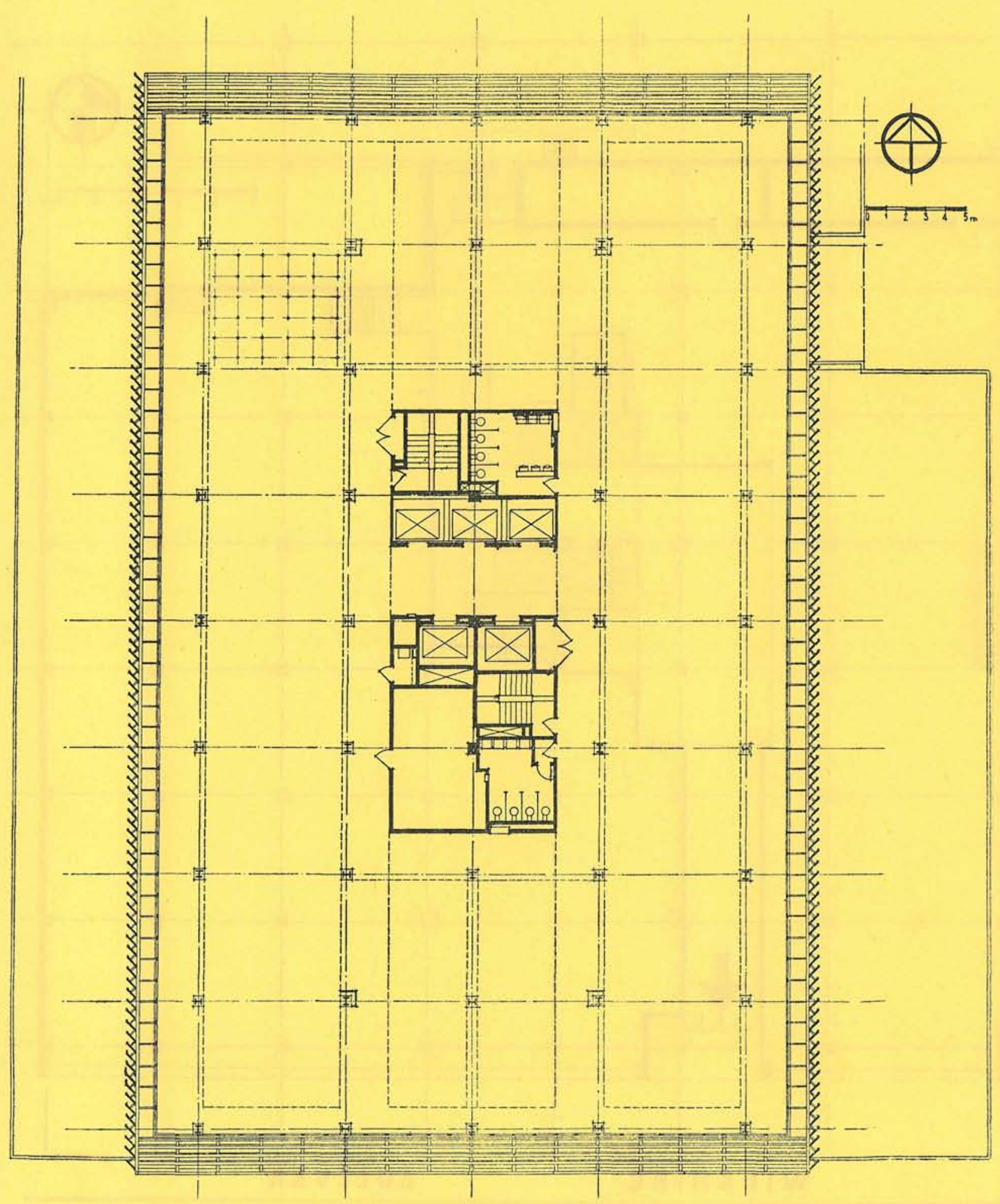




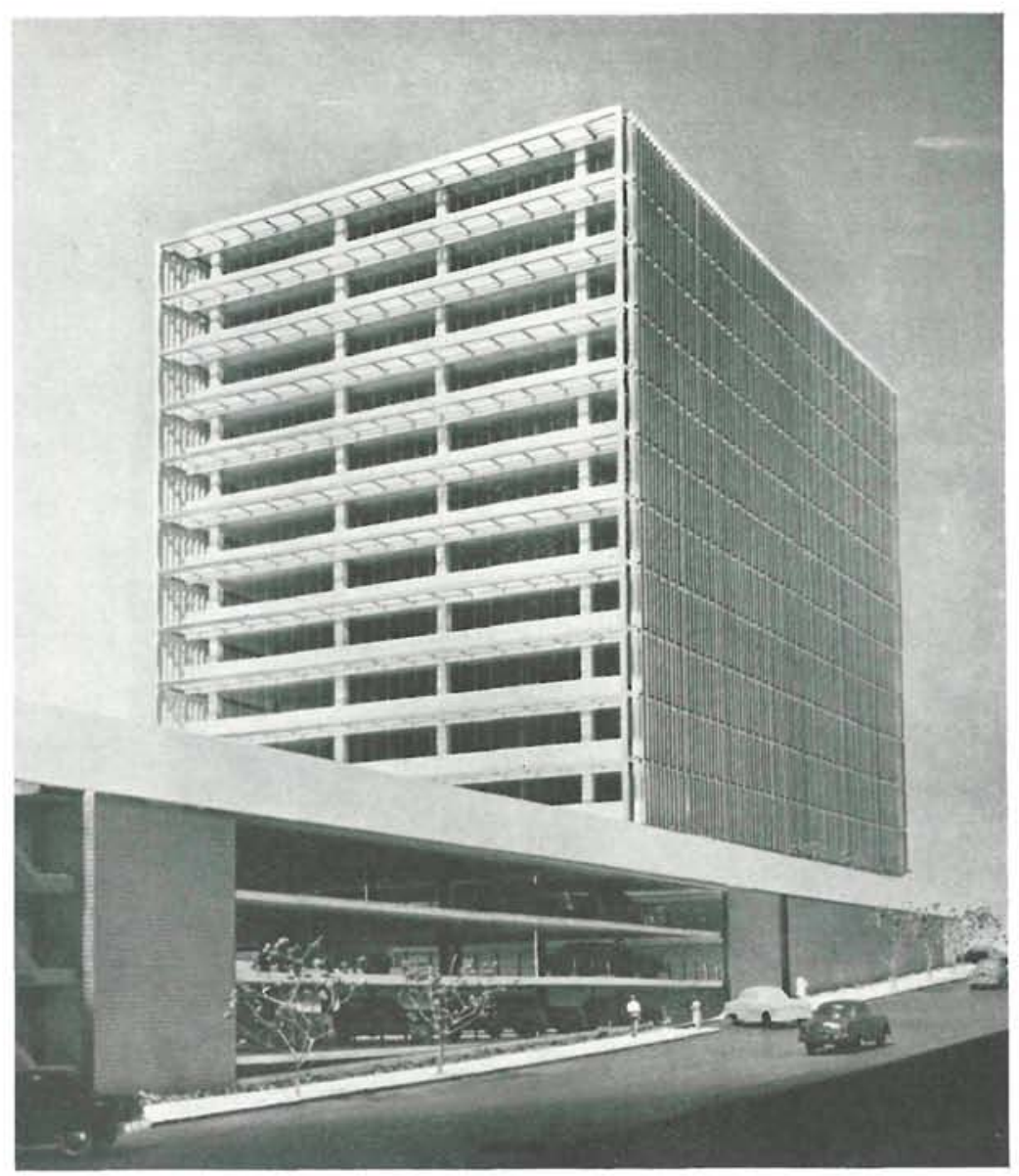

$\mathrm{maqueta}$

fachada este

Al muro de fachada resistente y opaco se opone ahora una estructura con forjados en voladizo en sus extremos, fachada acristalada y pantalla de protección solar. Que la solución es buena lo confirma el hecho sorprendente de que, en los edificios "todo cristal", se trabaja a todas horas con la persiana interior echada y la luz artificial encendida, haciendo destacar que su origen no se basa en una solución racional, sino en un alarde formal y constructivo.

Los parasoles de este edificio acusan, en sus fachadas oriental y occidental, una gran verticalidad, gracias al empleo de perfiles de aluminio, en $\mathrm{Z}$, que se elevan en toda la altura del edificio. Es en estas fachadas donde esta pantalla calada avanzada sobre el cerramiento acristalado del edificio, acusa con más fuerza la originalidad de su solución. La luz y temperatura están perfectamente controladas, si bien a base de coartar las vistas desde el interior, solución aceptable en un edificio de oficinas.

En las fachadas N. y S., los parasoles adoptan la forma de voladizos horizontales, que marcan la separación entre plantas, formando un conjunto más equilibrado y de menor novedad.

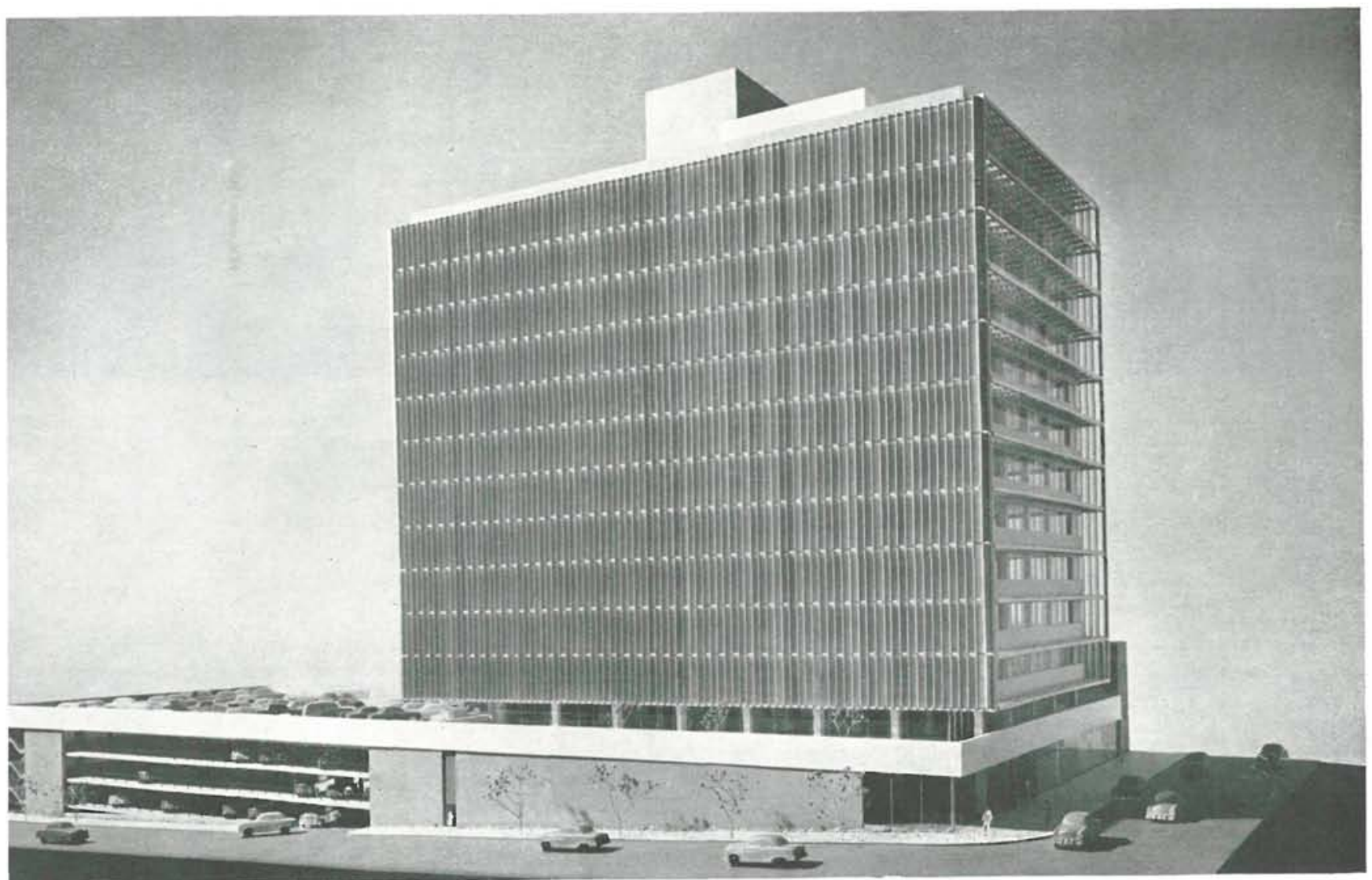




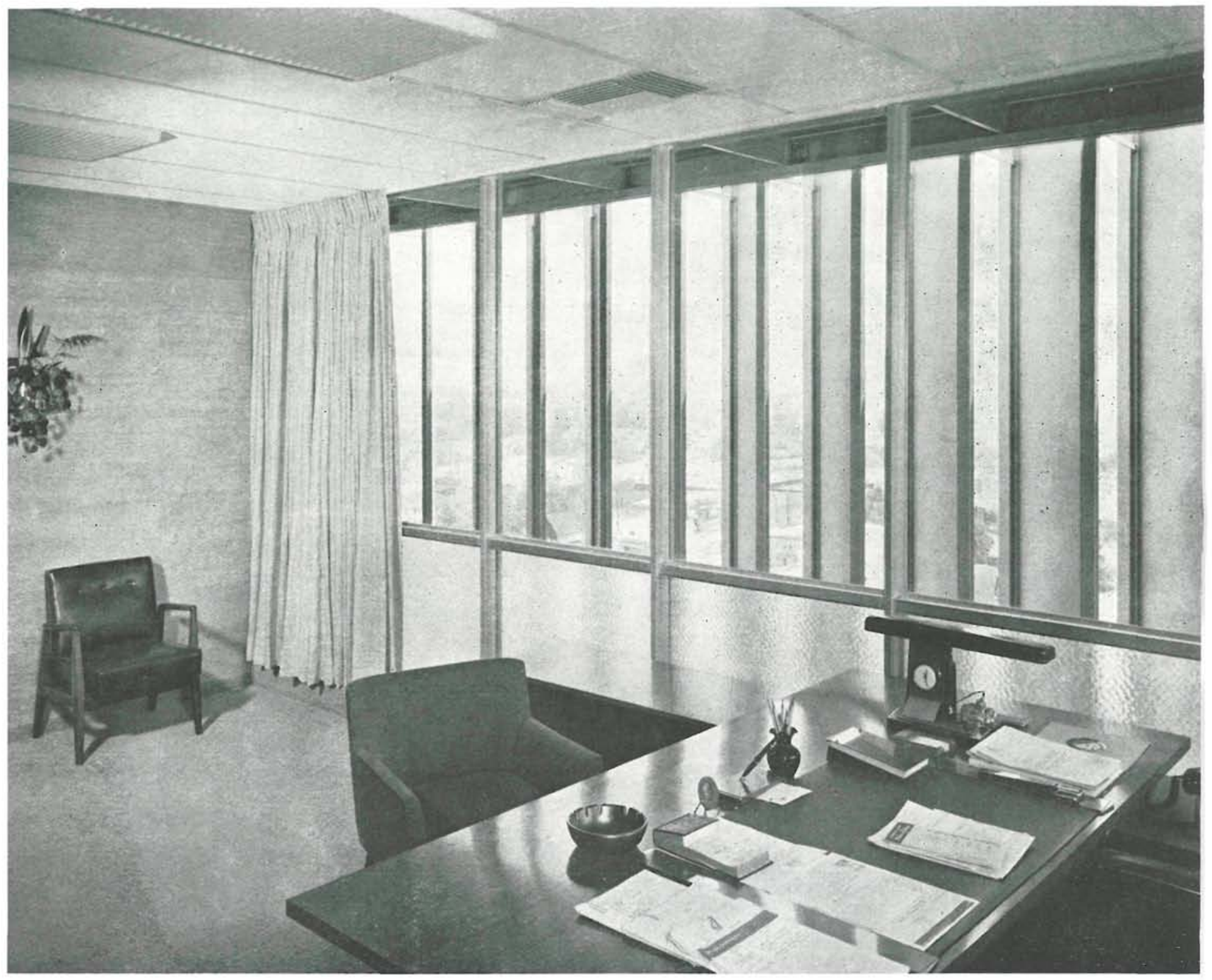

Tanto en una como en otra fachada se ha conseguido la perfecta iluminación de las zonas de despachos de oficinas, al mismo tiempo que se elimina la acción molesta del rayo solar directo y de fuertes desequilibrios térmicos locales, cosa que no impide la solución de persiana interior.

El cuerpo alto, de trece plantas, se eleva destacado sobre el cuerpo inferior, que forma el basamento de la edificación y que, aprovechando el desnivel del terreno, adopta, desde una planta en su fachada principal, hasta cuatro en la posterior. Este cuerpo inferior-de gran horizontalidad-está resuelto con paramentos de ladrillo rojo, coronados con una ancha cornisa blanca. En él se distribuyen diversos locales comerciales; un garaje, con capacidad para 350 automóviles, para uso del personal del edificio, y una terraza ajardinada con superficie de estacionamiento de coches para visitantes. 

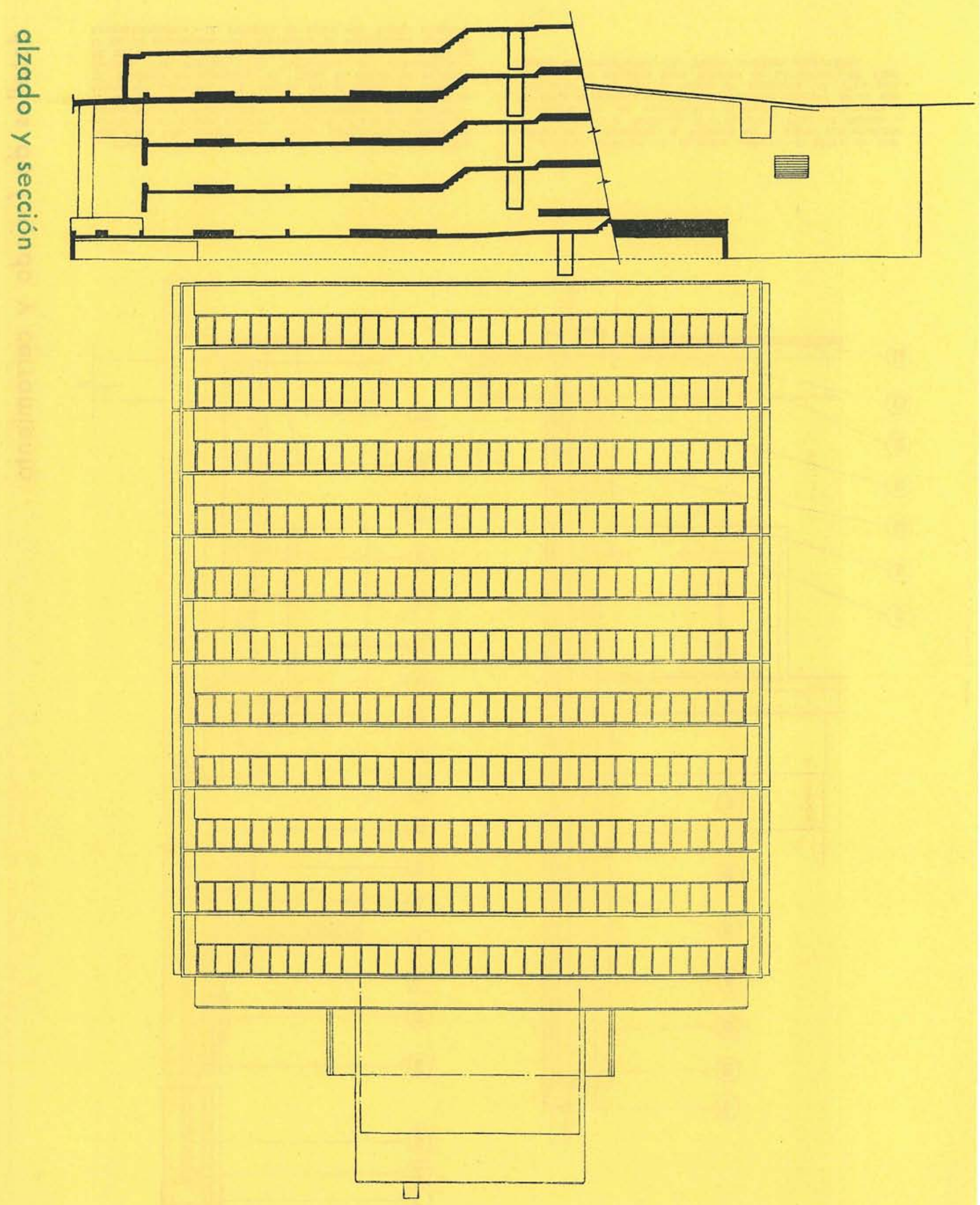

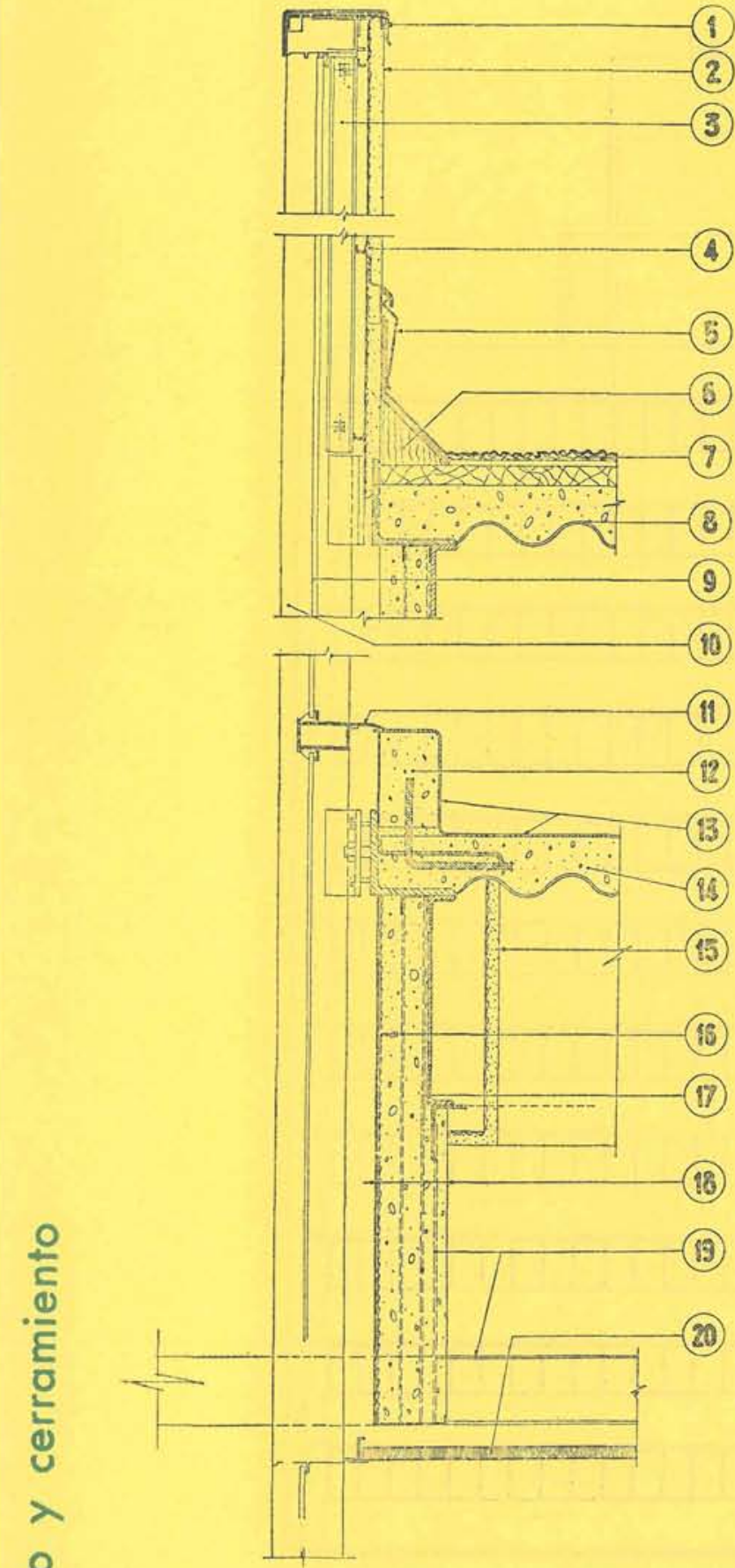

(20)

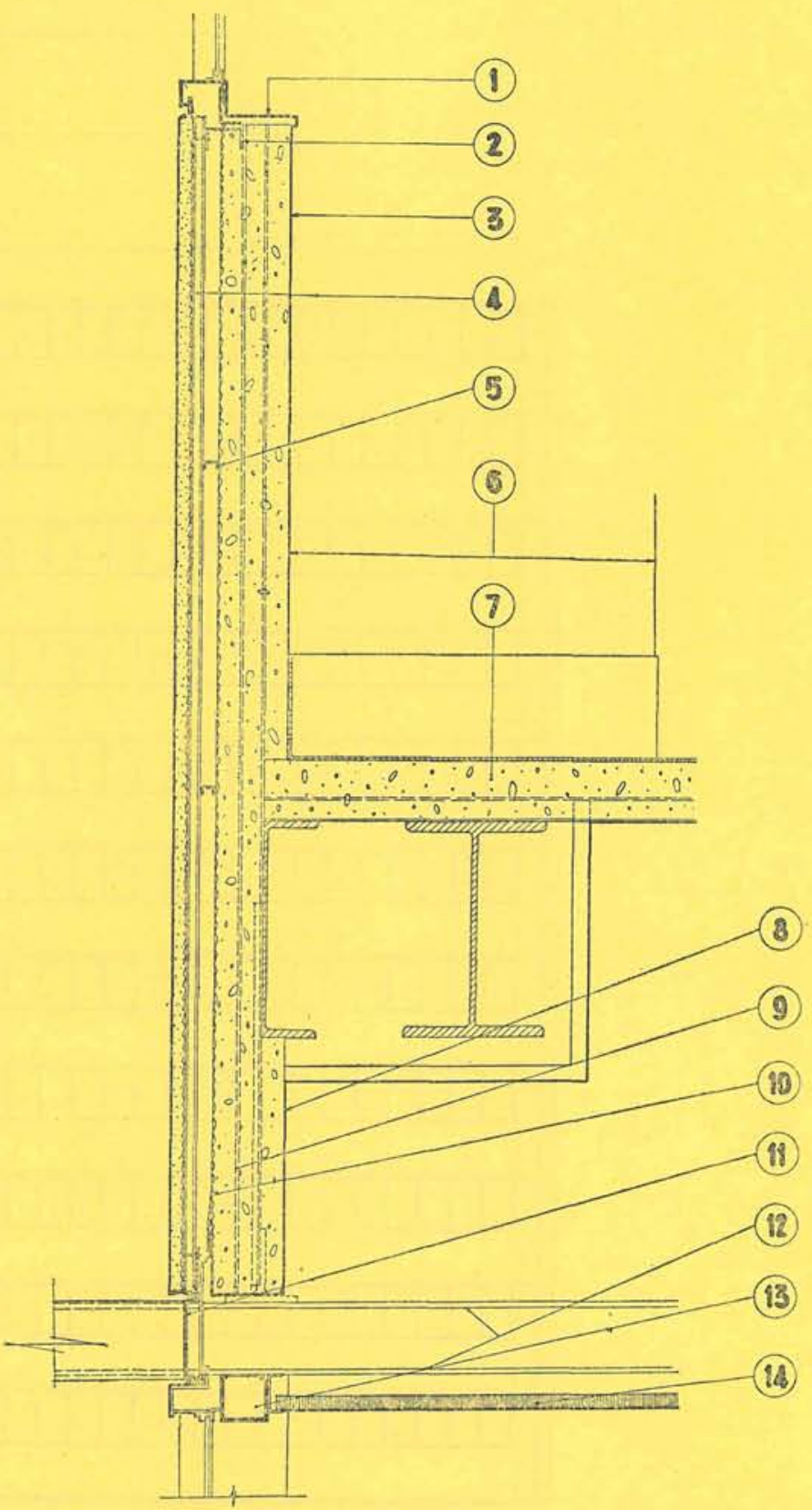

1. Placa continua de acero de $2,6 \mathrm{~mm}$ de espesor, -2 . Enlucido sobre tela metálica. -3 . Chapa atornillada al cerco de aluminio.-4. Listón metálico en U.-5. Placa de impermeabilización. - 6. Cantonera. - 7. Aislamiento del solado. 8. Cielorraso.-9. Paño de cristal o porcelana.-10. Montante de aluminio. - 11 . Banda de aluminio de cierre.12. Rodapié de hormigon.-13. Capa de solado de material flexible. - 14. Forjado. - 15. Tabiquillo de vermiculita, 16. Tela metalica para soportar la vermiculita. -17 . Perfil en $\checkmark$ de 38 millmetros. 18 . Hormigon de vermiculita aplicado
1. Alféizar metálico,-2. Angular soporte,-3. Muro de hormigón de vermiculita,-4. Vigueta en U atada con alambre 8. Hormigón de vermiculita aplicado neumáticemente9. Fleje o péndola soldada.-10. Soporte exterior de la vermiculita, -11 . Chapa de cierre de alumínio,-12. Viga vro longada en ménsula para fijación de parteluces.-13. Conducto de ventilación,-14. Techo acústico suspendido. 

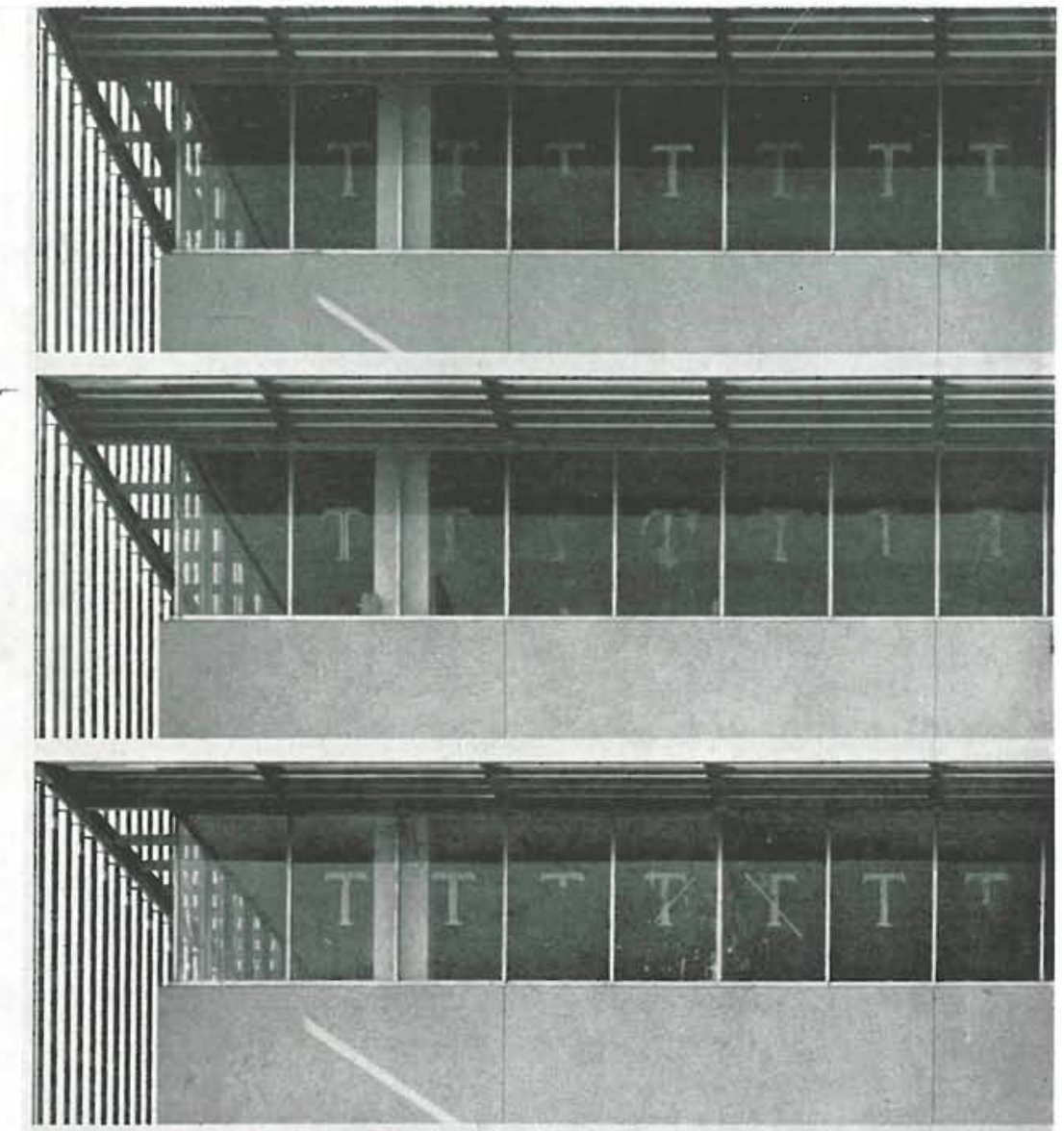

\section{QITIZENS NATIONAL BANK}

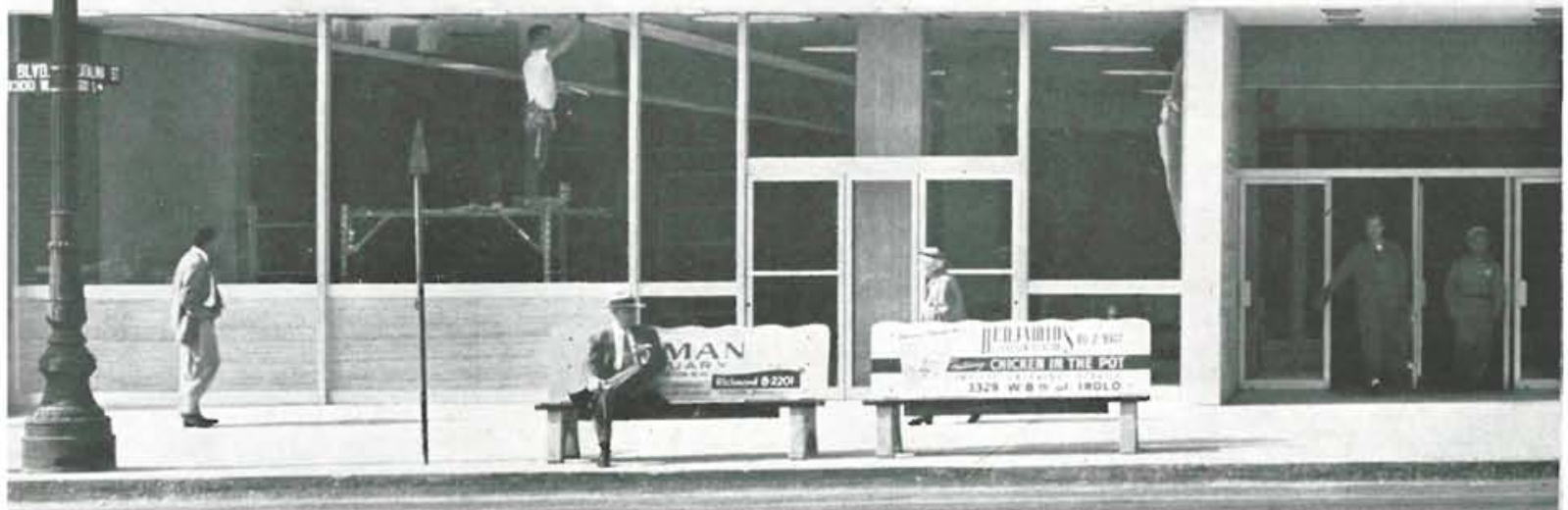

La estructura resistente es metálica, formando pórticos de siete metros de luz y de separación entre ejes, y sin ningún muro interior que exija una distribución especial, excepto los que forman el núcleo central de servicios, en el que se distribuyen los ascensores, escaleras y aseos.

Las ménsulas de sujeción de los parasoles de fachada, prolongación en voladizo de las viguetillas de sujeción del cielorraso, sirven de corredor seguro para el tránsito del personal encargado de limpieza de las superficies vidriadas. En el interior se emplean: forjados de chapa metálica ondulada y capa de hormigón, placas acústicas en los techos, tabiques móviles de distribución y cerramiento exterior acristalado, con placas de vidrio armado en los antepechos. 